\title{
LA ÉTICA EMPRESARIAL COMO GREACIÓN DE VALOR
}

\author{
Máximo Ugarte Vega Centeno* \\ E-mail:mugartev@unmsm.edu.pe \\ iiadm@unmsm.edu.pe
}

\begin{abstract}
RESUMEN
El cambio de siglo ha traído nuevas exigencias tanto en la economía, la tecnología e Internet, las que han acentuado la divulgación de los conocimientos y el incremento del rol social de las empresas en el avance de las organizaciones, así como su creciente papel en las sociedades. Es allí donde surge la ética como creación de valor, en razón de la transparencia de las conductas empresariales que benefician a toda la comunidad y a la empresa misma, además de evitar las consecuencias jurídico-legales que conllevarían su no práctica.
\end{abstract}

Palabras clave: Ética empresarial.

\begin{abstract}
The century change has brought new demands in the economy, the technology and the Internet, that have accentuated the popularization of knowledge and the increment of the social role of the companies, in the advance of the organizations, as well as the growing paper in the societies.

In this context, the ethics arises as creation of value, in reason of the transparency of the managerial behaviors that benefit the whole community and the company itself, besides avoiding the juridical-legal consequences, that would happen as a result of its non-practice.
\end{abstract}

Key words: Enterpreunal ethics.

\section{INTRODUCCIÓN}

En las relaciones empresariales y particularmente en la realización de un negocio, la omisión de información o la desinformación a terceros pueden llevar a que una organización se beneficie lucrativamente, pero también a que si se descubre la omisión o falsedad sea sancionada económica y jurídicamente.

Ante estas conductas es cuando se plantea la reflexión de la ética; en ese sentido la ética -como creación de valor- viene generando posiciones distintas. Una de estas posiciones está vinculada con la idea de que es imposible unir los negocios con los valores; es decir, un negocio bueno en el sentido moral es un mal negocio en el sentido económico. Estas nociones son inducidas por conceptos como competitividad, búsqueda del lucro, éxito profesional o la cultura de resultados inmediatos generada por falta de comunicación, transparencia, decisiones o estilos gerenciales. Otra posición señala que sería un error tener una visión

Doctor en Estudios Internacionales. Magíster en Estudios Europeos (Mercados de Integración Económica Comercial y Financiera). Profesor principal de la Facultad de Ciencias Administrativas y Director de la Unidad de Investigaciones de la Facultad de Ciencias Administrativas (UNMSM). 
o enfoque solamente de beneficio o de sacar una ventaja puramente económica, olvidando que los negocios se realizan a través de personas que vienen a ser los responsables de su desarrollo.

Podemos afirmar que una buena actitud ética es una buena actitud profesional frente a la sociedad, junto con la honradez, la veracidad y la honestidad. De esta manera la ética empresarial, entendida como comportamientos basados en los valores, beneficia a toda la sociedad, a la empresa misma y evita riesgos jurídico-legales.

\section{HIPÓTESIS}

La incorporación de la ética en las organizaciones evitaría riesgos jurídico-legales y generaría creación de valor; además, su inclusión al interior de las empresas debería convertirse en una estrategia organizacional.

\section{ANÁLISIS Y DISCUSIÓN}

Por las características del estudio descriptivo tomaremos en consideración tres indicadores: la incorporación de la ética en las organizaciones, la incorporación de la ética en las organizaciones evitaría los riesgos jurídicos y la ética como factor de creación.

\section{La incorporación de la ética en las organizaciones}

Al comentar sobre la ética necesariamente tenemos que recurrir a la filosofía. La palabra "ética" viene del griego "ethos". Aristóteles se refería a "éthos" como temperamento, carácter, hábito, modo de ser; en cambio otros autores se referían a su significado como suelo firme, fundamento en la praxis, raíz de donde brotan todos los actos, o que viene del concepto de la morada o lugar donde se habita referido al hombre o los pueblos.

La ética puede ser definida como el estudio de lo moral, que trata de regular la actividad humana en razón del bien, y se caracteriza por ser reflexiva -porque estudia los actos no como son, sino como deberían ser-, y es práctica por estar orientada a la acción humana. Otros autores, en cambio, la explican como reglas y principios que definen una conducta correcta o incorrecta ${ }^{1}$.

Para entender mejor la creación de valor es necesario hacer algunas diferencias entre la moral, valor, la ética y el código de ética. La moral se refiere a las costumbres, los actos y los pensamientos humanos, en especial desde el punto de vista de su bondad o malicia ${ }^{2}$. El valor viene a ser las convicciones básicas acerca del bien o del mal; otros señalan que es la cualidad o conjunto de cualidades que hacen que una persona o cosa sea apreciada ${ }^{3}$. El valor no lo poseen los objetos por sí mismos, sino que éstos lo adquieren gracias a su relación económica - social; en cambio, lo ético trata de la valoración moral de los actos humanos o el conjunto de principios y normas morales que regulan las actividades humanas ${ }^{4}$. Y, cuando hablamos de empresa, la definimos como una sociedad mercantil de producción de bienes y servicios. En cambio cuando nos referimos al código de ética, entendemos como la declaración formal de los valores fundamentales de una organización y las normas éticas que espera que sus trabajadores sigan.

Ahora bien, para el desarrollo de estas organizaciones, es importante el factor humano que dirige e integra estas empresas, ya que son las personas las que conducen a las organizaciones a desarrollarse, y por las acciones que realicen, ya sean correctas o incorrectas, se determinará el beneficio o perjuicio desde el punto de vista ético-empresarial. En ese sentido sería un error tener una visión solamente economicista, olvidando que los negocios se realizan a través de personas que vienen a ser los responsables de las actividades de la empresa. Por eso, estando de acuerdo con otros autores, señalamos que una buena actitud ética es una buena actitud profesional, por lo tanto una buena actitud ética es una buena actitud profesional frente a la sociedad junto a la honradez, veracidad y honestidad ${ }^{5}$.

\section{La incorporación de la ética en las organizaciones evitaría los riesgos jurídicos}

Podemos encontrar los primeros antecedentes de responsabilidad de la empresa ante las leyes de un Estado, y sujeta a derechos y deberes igual que las personas naturales, en la sentencia del Tribunal Supremo de Estados Unidos. Con su resolución en Dartmouth College versus Woodward de 1819 , reconoce a la empresa con personalidad jurídica; es decir, que podía realizar operaciones, contratos de personal, adquirir bienes, etc. Décadas después, en 
1909, el mismo Tribunal dicta la Resolución de Nueva York Central Railroad versus United States, sobre la responsabilidad jurídica por los hechos que hubieren generado los trabajadores; en otras palabras, se indicaba que había responsabilidad corporativa al margen de la responsabilidad penal personal de los trabajadores. A partir de 1970 surge la incorporación de la ética empresarial como responsabilidad social corporativa. Desde luego, no fue un camino fácil por las reticencias en los empresarios a extender el ámbito de responsabilidades normativo-legal al ámbito ético-social como lo demuestran los juicios en los tribunales donde las empresas terminaron por aceptar sus responsabilidades e indemnizaciones respectivas en las diferentes sentencias judiciales. Las empresas se resistían a que se pasara de una responsabilidad penal de carácter legal a una de responsabilidad social-ética, argumentando que las empresas ni tenían cuerpos a encarcelar ni almas que condenar y que la sociedad no les podía imponer actos filantrópicos; y que, además, el dinero que ganaban era de su propiedad y podían hacer lo que quisieran siempre y cuando no hicieran daño a terceros. En los 80 se difunden masivamente denuncias de comportamientos nada éticos en las empresas como acoso sexual, fraude fiscal, publicidad engañosa, etc., para sensibilizar a la sociedad contra estas prácticas anti-éticas.

La segunda "incorporación" de la ética empresarial se da en el contexto de los años 90 con la ratificación del Congreso de Estados Unidos en relación a los Federal Corporate Sentencing Guidelines. Con esta ley quedaba en evidencia el riesgo que corrían las empresas que no incorporaban la ética en sus diferentes operaciones, debido a las sanciones económicas que los Tribunales podrían imponerles por sus infracciones y delitos en este ámbito.

Podemos apreciar que existe un proceso de evolución de una responsabilidad social corporativa a una autorregulación, proceso que ha empezado a surtir efectos y que ya aparece en las legislaciones de Estados Unidos y de la Unión Europea $^{6}$, lo que ha contribuido al impulso, institucionalización y colección metódica de los principios de la ética.

\section{La ética y la normatividad jurídica de la empresa en el ámbito nacional}

Entendiendo que la composición de la empresa no sólo incorpora a empresarios, trabaja- dores y comunidad, sino también normas y valores, se han generado diferentes definiciones de empresa que la mayoría de los ordenamientos jurídicos del derecho comparado ha evitado precisar o definir.

En nuestra normatividad jurídica no se ha conceptualizado a la empresa por estar enfocada desde el punto de vista comercial que giró en torno al comerciante. En el proyecto de Ley Marco del Empresariado recién podemos encontrar una definición: "organización económica dedicada a la producción o comercialización de bienes o a la prestación de servicios". De esta definición se puede observar que existen dos enfoques: el estático y el dinámico. El primero toma en consideración todos los elementos aislados de la empresa como maquinaria, capital, trabajadores, materia prima, inmuebles, sin ninguna interrelación; en cambio, el enfoque dinámico, si bien observa los mismos elementos que el supuesto anterior, los vincula con el destino económico único y está referido a una idea organizadora: "la empresa es un círculo de actividades dirigidas por la idea de la organización; es al mismo tiempo presupuesto racional de trabajo de la empresa y el resultado de ese mismo trabajo" ".

De otro lado, la aparición de la empresa en el escenario jurídico configura literalmente un evento extraordinario y sorprendente, que exigía aceleradamente una respuesta que se da con el surgimiento del derecho empresarial; sin embargo, este nuevo derecho creó muchos debates y desacuerdos entre los especialistas de derecho comercial y mercantil. El principal problema que afronta es en relación a su autonomía; para ello debemos tener en consideración que este derecho gira en torno a la empresa: su actuación se circunscribe al conjunto de normas jurídicas relativas a los empresarios y a los actos que surgen en el ejercicio de su actividad económica.

El Derecho Empresarial presenta un contenido multidisciplinario por tratarse del estudio de una institución tan compleja como es la empresa, que abarca los aspectos civil, laboral, mercantil, tributario, concursal, entre otros y muchas veces incurre u omite en actos ilícitos como los delitos societarios, laborales, delito de quiebra, contra la propiedad intelectual, contra el orden económico, contra el consumidor, represión a la competencia desleal y delitos financieros (que son los más frecuentes), actos ge- 
nerados por la complejidad de su actividad que produce un conjunto de conductas que buscan beneficiarse a expensas de los demás, afectando a la actividad económica y a la planificación estatal de la economía, buscando que pasar por alto las normas estatales que organizan y protegen la vida económica, por lo que la delimitación de estos delitos es trascendental ${ }^{8}$. Consecuentemente, la pregunta es dónde se encuentra regulado lo ético.

En términos generales, podemos afirmar que existen normas reguladoras de la conducta humana que a través del tiempo demuestran que el hombre es esencialmente social: nace perteneciendo a una familia para luego integrarse a un colegio, un centro de trabajo, pueblo, nación. Por lo tanto, el hombre ya no puede actuar arbitrariamente ya que la propia vida social está regida por normas reguladoras de la conducta humana, entre las que podemos citar a las normas técnicas y las éticas. Las normas técnicas se refieren a las reglas y principios que tiene toda actividad de trabajo, servicio, asesoramiento, entre otros; en cambio las normas éticas regulan la conducta humana frente a los demás y pueden ser normas religiosas, morales, de sociabilidad y normas jurídicas. En otras palabras, toda sociedad requiere de normas jurídicas que emana y precisa el derecho, como las que obligan a realizar determinados actos o contrariamente impone prohibiciones.

En ese sentido, como bien sabemos, la ética es el código de principios morales que modela el comportamiento de una persona, grupo u organización con respecto a lo que es correcto o incorrecto. Los valores éticos establecen normas en cuanto a lo que es bueno o malo en la conducta y en la toma de decisiones.

La ética es diferente de los comportamientos regulados por ley. Las leyes gubernamentales surgen de un conjunto de principios y regulaciones codificadas que describen la forma cómo la gente ha de actuar; generalmente son aceptadas en la sociedad y se pueden hacer cumplir mediante el poder judicial (Jueces, tribunales, etc). En cambio las normas éticas, en su mayor parte, se aplican a una conducta que no está prevista por la ley; además la ley gubernamental cubre comportamientos que no necesariamente abarcan las normas éticas.

Con frecuencia las leyes actuales reflejan juicios morales combinados, pero no todos los juicios están codificados en leyes. En ese sentido, existen muchas conductas que no se han codificado en nuestro sistema jurídico y los responsables de las organizaciones deben ser sensibles a las normas y valores emergentes de su entorno interno e externo. En lo interno, la noción de responsabilidad social ${ }^{9}$ es una extensión de esta idea cuando se refiere a la obligación de los gerentes de tomar decisiones y emprender acciones para que la organización contribuya al bienestar e intereses de la sociedad y de ella misma ${ }^{10}$. En lo externo, en el Perú tenemos que seguir reforzando los grandes valores a cultivar, valores que muchas veces nos asustan, nos conmueven, nos sacuden y que tienen que seguir afrontándose en distintos ámbitos: en lo moral (derechos humanos), en lo político (respeto al estado de derecho y sus instituciones), en lo social (la pobreza) y en lo jurídico (la lucha contra el crimen organizado en sus diferentes expresiones); en este caso la criminalidad económica con decisiones sustantivas y orgánicas dentro del sistema de administración de justicia penal.

\section{LA ÉTICA COMO FACTOR DE CREACIÓN DE VALOR}

Lo ético comprende la intención de las organizaciones de actuar con transparencia en sus relaciones empresariales; como dice Rinnov Kan, sin valores sólidos estamos coqueteando con el desastre. Con valores sólidos podemos enfrentar a los mercados internacionales; en otras palabras, con la ética corporativa se pueden lograr ventajas competitivas tales como atraer clientes y personal calificado, y se pueden desterrar prácticas corruptas que perjudican el valor y la economía de un país.

En ese sentido, coincidiendo con muchos autores, para desarrollar el valor ético en la empresa debemos empezar a diferenciar cuatro fases que describen el contenido de cómo se construye una empresa: la creación, la diferenciación, la unificación y la congregación. La primera fase se refiere a una o varias personas que emprenden una actividad lucrativa. La segunda, se refiere a la diferenciación que se da principalmente en dos aspectos sustanciales, tales como la titularidad y el patrimonio (titularidad se entiende a disimilitud entre persona jurídica, titular de empresa y el empresario, y en relación al patrimonio es distinguible el perteneciente a la 
persona jurídica del que corresponde al empresario que se expresa en lo que conocemos como sociedad anónima). La tercera fase, conocida como unificación, se refiere al patrimonio de la persona jurídica y se concibe como la sumatoria de elementos aislados, máquinas, dinero y materia prima; posteriormente, se unen las marcas, acciones, derechos, tecnología, patentes, canales de distribución y la conjunción de todo ello con la actividad que desarrolla es conocido como empresa; entonces podemos decir que este es el momento más importante de la evolución de la empresa.

Como última fase tenemos la congregación; es decir, cuando la empresa extiende sus alcances a diferentes grupos de la sociedad. Es en ese momento en el que nace la congregación, ya que con el desarrollo de la comunicación y la tecnología se canalizan en la empresa recursos que pueden ser proporcionados por un número reducido de titulares, donde conviven inversionistas, trabajadores, consumidores y usuarios, acreedores y el Estado.

$\mathrm{Si}$ incorporamos a estas cuatro fases arriba mencionadas los valores éticos, se generarían mejores conductas y valor, siempre y cuando se incorpore a la organización valores básicos como la igualdad, libertad, dialogo, respeto y solidaridad ${ }^{11}$.

Si se logran estos valores se puede llegar a generar mayor valor económico; por lo tanto, la ética ayuda a mejorar la organización y el funcionamiento de la empresa mediante varias vías. Como indica Carlos López ${ }^{12}$, la ética reduce los conflictos de los miembros que forman la empresa, mejora la imagen exterior de sí misma, y supone un componente esencial del concepto de "calidad total", tan importante en estos días.

\section{La inclusión ética como estrategia de las empresas}

Como hemos visto anteriormente, las exigencias del mercado cada vez son mayores y la ética, en su concepto tradicional, ha ido evolucionando y cada vez es más difícil emitir un juicio apropiado sobre cómo podemos atribuir una conciencia corporativa empresarial. Sin embargo, la incorporación de valores en los recursos humanos como estrategia para cambiar la forma de pensar, el trabajo en equipo y la comunicación, la cultura de la confianza y, en general, una cultura empresarial, contribuirían a generar un ambiente adecuado y más humano dentro de la empresa, que reemplazaría a la práctica coercitiva-burocrática que muchas veces ha sido lo más común. La ética, por lo tanto, tiene influencia en las relaciones empresariales y, como consecuencia, en los resultados.

La aplicación de instrumentos de valoración de gestión ética que pudieran ayudar a demostrar quiénes realmente están implicados con los valores de la organización, es una opción que ayudaría a determinar la gestión de la empresa con responsabilidad y transparencia. Sin embargo, la práctica de qué es el criterio de la verdad demostrará si las actitudes son buenas o malas en la empresa y se premiará o sancionará.

\section{CONCLUSIONES}

1. La globalización nos ha traído nuevos retos y exigencias en las relaciones económicas y empresariales, donde la ética toma más relevancia y cada vez se hace más exigente.

2. Para que la ética no quede en palabras o dichos, es importante institucionalizarla mediante normas y actitudes de honestidad, para así evitar los riesgos jurídicos-legales.

3. La ética empresarial no es un valor añadido, sino un valor intrínseco de las organizaciones.

4. El fortalecimiento de los valores y principios de las organizaciones tiene efectos en el capital humano.

5. Es importante generar una cultura de responsabilidad y principios éticos.

6. La transparencia viene a ser un valor intangible de toda organización por lo que se procura que la empresa, frente a la sociedad, tenga un comportamiento honrado, veraz y honesto.

7. La actitud transparente de las personas que integran una organización se exteriorizará en las actividades que realicen dentro y fuera de ella.

8. Si la ética se incorporase como una exigencia estratégica en toda empresa, se evitarían los riesgos jurídicos-legales en que pudiera incurrir la organización si no actuara bajo sus principios. 
9. Y, por último, podemos decir que seguirá siempre en agenda el conflicto no resuelto entre la ética y los beneficios económicos.

\section{NOTAS}

1. Ver Robbins, Stephen y Coulter, Mary. (1996). Administración. Quinta Edición en español. Editorial Prentice-Hall Hispanoamericana SA., p. 159 y ss.

2. Editorial Planeta. (2001). Diccionario básico de la lengua española. Barcelona, Editorial Planeta, p. 943.

3. Ibid, p. 1461

4. Ibid. p. 590.

5. Véase, entre otros, Polo Santillán, Miguel Angel. (2003). Ética profesional. En: Revista Gestión en el Tercer Milenio. Lima, Facultad de Ciencias Administrativas de la UNMSM. Año 6, $\mathrm{N}^{\circ} 12$, diciembre 2003, p. 69-78; ver también Vuelva, Julio. (2002). Ética profesional de enfermería. Bilbao, Desciré de Brouwer.

6. Ver, por ejemplo, la Foreign Corrupt Practices en la que se declara ilegal el pago y la oferta de pago en dinero o especie, directa o indirectamente, a funcionarios representantes electos para influir o conseguir una venta o un contrato para una empresa norteamericana. Véase también las leyes anti corrupción de actos, extorsiones, sobornos en general, con relación a los gobiernos locales, estatales y federales de los Estados Unidos en Anti-Kicbak
Act of 1986, Byrd Amendment, Federal Election Campaign Act, entre otros.

7. De la Puente y Lavalle, Manuel. (1997). Contenido de Derecho Mercantil Moderno. En Revista de Estudios Privados. Lima, Facultad de Derecho de la Universidad de San Martín de Porres, Año 2, № 2, 1997, pp. 13-14.

8. Ver Ugarte Vega Centeno, Máximo. (2003). El Derecho penal económico como alternativa en la solución de los llamados Delitos Económicos Empresariales. En Revista Gestión en el Tercer Milenio. Lima, Facultad de Ciencias Administrativas de la UNMSM, Año 6, № 12, Diciembre 2003, pp. 35-39. Véase también Torres y Torres Lara, Carlos. (1985). Persona y Empresa. En Revista Peruana de derecho de la Empresa - Separata Doctrinaria. Lima, Edit. Asesorandina, Abril 1985, p. 1-62. Ver Mena Ramírez, Miguel. (1986). La empresa en el Perú. Edit. Cuzco, p. 237.

9. Véase Ugarte Vega Centeno, Máximo. (2005). La empresa como agente de cambio y desarrollo. En Revista Gestión en el Tercer Milenio. Lima, Facultad de Ciencias Administrativas de la UNMSM, Vol.7, $\mathrm{N}^{\circ} 14$, Noviembre 2005, pp. 54 y ss.

10. Sobre responsabilidad social y desempeño económico ver Robbins, Stephen y Coulter, Mary. Administración. Op.cit., pp. 151 a 154. Del mismo autor, sobre ética gerencial, pp. 158 a 183.

11. López, Carlos. La ética empresarial como fuente de ventaja competitivas. En http//www.gestiopolis.com/canales/ gerenciales, p. 2.

12. Ibid. p. 2-3. 